\title{
Analysis of densification mechanisms of dry granulated materials
}

\author{
S. Uniyal ${ }^{\text {a,* }}$, L.P. Gandarillas ${ }^{\text {a }}$, M. Michrafy ${ }^{\text {b }}$, D. Oulahna ${ }^{a}$, A. Michrafy ${ }^{a}$ \\ ${ }^{a}$ Université de Toulouse, Mines Albi, CNRS, Centre RAPSODEE, 81000 Albi, France \\ ${ }^{\mathrm{b}}$ Kedge Business School, 680 cours de la Libération, 33405 Talence, France
}

Keywords:

Dry granulation/roll compaction

Granules densification

Cooper-Eaton model

Adams model

\begin{abstract}
A B S T R A C T
Dry granulation by roll compaction is a continuum manufacturing process to produce granules with improved flowability which can further be easily used in tableting process. However, the granules are non-homogeneous in density and have non-spherical shapes which impact their densification behaviour during die-compaction. The aim of this study was to investigate both the densification mechanism and the failure strength of granules of microcrystalline cellulose (MCC) and mannitol using Cooper-Eaton and Adams models. For both materials, the Cooper-Eaton approach led to the quantification of fractional volume compaction by particle rearrangement and by plastic deformation respectively to explain the difference in densification behaviour of raw material and granules. Moreover, the model showed its ability to capture the effect of granule density and granule sizes and to differentiate the densification mechanisms of MCC as a plastic material and mannitol as a brittle material. The Adams model was used to compute the failure strength of single granule from in-die compression data. The obtained results of the granules were in the range [0.6-1.43 MPa]. However, regarding the effect of granule density, the model showed mixed results indicating that the model is not representative of the studied granules which are not spherical and have a relatively wide range of sizes, nevertheless, the model was derived for near spherical particles with a narrow size distribution.
\end{abstract}

\section{Introduction}

Dry granulation by roll compaction is a continuous manufacturing process often employed in the pharmaceutical industry to improve powder properties. In this process, the powders are compacted between two counter-rotating rolls to produce ribbons that are subsequently milled into granules. The granules with improved flowability are then used for further processes such as die compaction or capsule filling. The process is particularly used for materials which are sensitive to heat or moisture, as no drying stage is needed hence leading to a reduction in cost [1].

The effect of roll compaction process parameters such as roll force, sealing system design (which limits the loss of powder during the compaction) and milling conditions on ribbon, granules and tablets properties had been widely reported in the literature [27]. These process parameters are considered as the important parameters affecting the mechanical properties of the granules which ultimately affect their compressibility and compactibility [8-11]. In the recent work [6], the effect of different roll compaction and milling conditions on ribbons, granules and tablet properties

\footnotetext{
* Corresponding author.

E-mail address: sagar.uniyal@mines-albi.fr (S. Uniyal).
}

were studied for microcrystalline cellulose (MCC) and mannitol powders. It was found that the higher the roll force, the lower was the tensile strength of tablets from granules. Moreover, MCC, which exhibits plastic behaviour was more affected whereas mannitol which exhibits brittle behaviour does not show much difference.

During die compaction, the granules show different behaviour than feed powders and this observation had been reported many times in the literature as 'Loss of reworkability/loss of tabletability' leading to a reduction in tensile strength of tablets produced from granules [12-14]. It is also commonly observed that plastic materials are more sensitive to this phenomenon than brittle materials $[15,16]$. In the earlier paper $[16]$, the understanding of how granules behave differently from feed powders had been studied for MCC101 powder. The analysis was based on Drucker-Prager Cap model (DPC), which characterizes the Elastic-Plastic behaviour of powders and takes into account the main properties of the compacted material (cohesion, internal friction, hardening and breaking under shearing stress). It was shown that the material properties were density dependent and the values of the DPC parameters were lower for granulated powders as compared to feed powders. However, in this analysis, which was based on DPC model, the main studied behaviour concerned the plastic deformation of the material rather than the early and intermediate 
densification stages where the powder behaviour can exhibit differences in compressibility that can influence the further plastic deformation.

The compressibility describes the ability of the material to undergo volume reduction under pressure. This deformation is the result of several mechanisms ranging from particle rearrangement to plastic deformation or fragmentation of particles which are essential in the understanding of the compactibility [17]. However, such mechanisms generally depend on granules properties which are polydisperse both in density and size.

Many equations had been developed to describe the compressibility of powders [18-24]. The theoretical background along with the limitations of some of these equations had been reviewed in [25]. It was concluded that none of these equations were found to be satisfactory for the complete analysis of the mechanism involved in the compaction of powders. This may be due to the complexity of the compaction process consisting of particle rearrangement, elastic/plastic deformation or fragmentation [26]. Moreover, all pharmaceutical materials exhibit different behaviours. Plastic deformation plays a major role during compression of ductile materials whereas brittle material deforms mainly by fragmentation [27]. Out of all the empirical relations described in the literature, the model proposed by Cooper and Eaton [21] is a promising approach as it describes the densification behaviour of powders as a two-stage process i.e. particle arrangement and plastic deformation allowing to study the behaviour at both low and high pressure respectively. The model was originally developed for ceramic materials but later, many authors had successfully applied this model to study the behaviour of pharmaceutical materials [28-33]. For instance, the effect of particle size on the densification behaviour for microcrystalline cellulose and spray-dried lactose was studied and particle rearrangement was found to be the predominant mechanism for the smallest size fraction [28]. The compression behaviour of four different pharmaceutical powders having widely different particle size distribution and shape was studied and the usefulness of Cooper-Eaton method was suggested [30]. However, as per our knowledge, the study of densification mechanisms of roll granulated pharmaceutical powders based on Cooper-Eaton equation is rare in the scientific literature.

The aim of the present work is to analyse the densification behaviour of roll granulated powder by focusing on both stages of densification at low and high pressure, using Cooper-Eaton model. The analysis is conducted on two types of powders, MCC and mannitol exhibiting plastic and brittle behaviours, which were roll compacted at two different roll force. The attempt of this study is to progress in understanding (i) why granulated powder behaves differently than those of feed powders during die compaction, (ii) what is the effect of roll force on granule strength, rearrangement and plastic deformation and (iii) how the Cooper-Eaton model can differentiate the behaviour of plastic and brittle materials.

To go towards a better comprehension of the strength reduction of tablet from granules of plastic material by increasing roll compaction force (the higher the roll compaction force, the higher is the reduction of tablet strength from granules), an evaluation of granule strength based on the equation proposed by Adams and co-workers [24] was used to compute the single granule strength of MCC and mannitol from in-die compaction data.

\section{Materials and methods}

\subsection{Raw material}

Two common pharmaceutical materials were employed in this study as received from the suppliers: microcrystalline cellulose, MCC101, Avicel ${ }^{\circledR}$ PH-101 $\left(d_{50}=50 \mu \mathrm{m}\right)$ supplied by FMC Biopoly- mer (USA) and spray-dried mannitol, Pearlitol ${ }^{\circledR}$ 200SD $\left(d_{50}=170 \mu \mathrm{m}\right)$ from Roquette ${ }^{\circledR}$ (France). For each material, the bulk density was provided by the manufacturer. The scanning electron microscopy images (Philips, XL30, Netherlands) in Fig. 1 shows that MCC101 is needle shape, however spray-dried mannitol shows a more spherical particle shape.

\subsection{Dry granules preparation}

MCC 101 and mannitol were roll compacted using Gerteis MiniPactor $^{\circledR}$ 250/25 (Gerteis Machinen + Process engineering AG, Jona, Switzerland) which was equipped with two inclined setups of rolls (250 $\mathrm{mm}$ in diameter and $25 \mathrm{~mm}$ in wide) and cheekplates as a sealing system. The gap between the rolls was kept constant at $1.5 \mathrm{~mm}$ being controlled by the automatic feedback system and the speed of the rolls was $2 \mathrm{rpm}$. Two specific compaction forces of 4 and $8 \mathrm{kN} / \mathrm{cm}$ were used to produce ribbons. The roll force $(4 \mathrm{kN} / \mathrm{cm}$ and $8 \mathrm{kN} / \mathrm{cm}$ ) was randomly chosen but with the objective to produce ribbons with lower and higher relative densities. Once the steady state was achieved for each condition, ribbons of MCC 101 and mannitol were milled after compaction using the integrated oscillating granulator in the roll press [6]. In order to determine the ribbon density, solid fraction of different samples of $0.6 \times 1 \mathrm{~cm}$, cut from the ribbon, were measured using GeoPyc ${ }^{\circledR}$ 1360 envelope density analyzer. The obtained average relative density of the ribbon was assumed as the average relative density of the granules produced from corresponding ribbons. Bulk density of granules was measured by filling a volume of $1 \mathrm{~cm}^{3}$ of powder

(a)

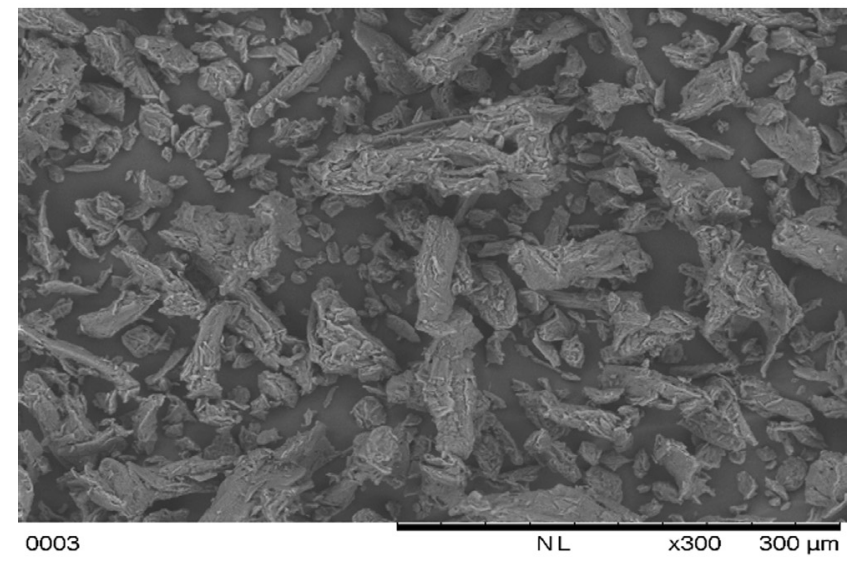

(b)

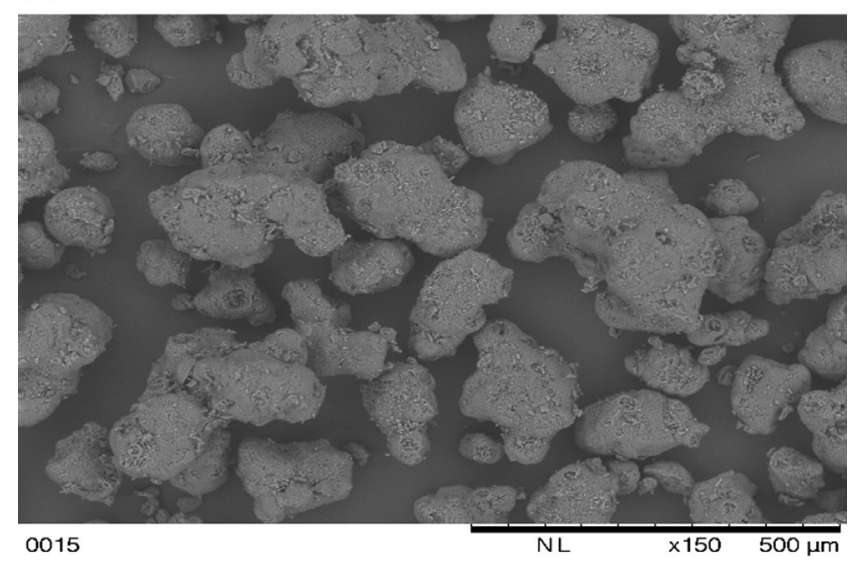

Fig. 1. Scanning Electron Microscopy images of the excipients (a) MCC 101 and (b) mannitol. 
and weighing the corresponding mass. The data were summarised in Table 1 and showed an increase in bulk density and relative density according to the increase of roll force.

With the objective to understand the effect of granule density and granule size on the densification process, two size classes of granules [250-500 $\mu \mathrm{m}$ ] and [500-1000 $\mu \mathrm{m}$ ], referred as "Small" and "Big" respectively, were generated by sieve technique. For convenience, we refer in the following to granules from ribbon compacted at $4 \mathrm{kN} / \mathrm{cm}$ as "Small- $4 \mathrm{kN} / \mathrm{cm}$ " and "Big- $4 \mathrm{kN} / \mathrm{cm}$ " and those compacted at $8 \mathrm{kN} / \mathrm{cm}$ as "Small- $8 \mathrm{kN} / \mathrm{cm}$ " and "Big- $8 \mathrm{kN} / \mathrm{cm}$ ".

It can be seen in Fig. 2 that SEM images of granules of MCC 101 present overall an agglomeration of fibre-like single particles and show smoother surface when they are compacted at $8 \mathrm{kN} / \mathrm{cm}$. However, the granules produced from mannitol at $4 \mathrm{kN} / \mathrm{cm}$ or 8 $\mathrm{kN} / \mathrm{cm}$ do not show noticeable differences in the surface aspect.

\subsection{Die compaction}

The powder compaction was studied using a full-instrumented eccentric press (Frogerais OA), which is fitted with a fixed cylindrical die having a diameter of $11.28 \mathrm{~mm}$ and a height of $10 \mathrm{~mm}$ [34]. The pressure is applied with the upper punch and the ejection is executed with the lower one. Both punches are flat. For each powder (raw material and granules), a mass of $0.3( \pm 0.01 \mathrm{~g}$ ) was weighted using a Sartorius CP2245 balance having a precision of
$0.001 \mathrm{~g}$. The powder mass was then manually poured into the die (which was pre-lubricated in the case of mannitol) and pressed assuming a fixed maximum displacement of $7.5 \mathrm{~mm}$ for MCC 101 and $7 \mathrm{~mm}$ for mannitol. The resulting pressure and time of compaction were recorded accordingly. The average loading rate of the compaction was computed from maximum displacement of the upper punch and time of loading was in the range [1-1.5] $\mathrm{mm} / \mathrm{s}$. All the tests were replicated at least three times. The absolute variation in pressure was less than $0.5 \%$. In further analysis, the average of the data was considered.

Pressure versus displacement curves of raw material and granules of MCC 101 and mannitol were plotted in Fig. 3(a) and (b) respectively.

\subsection{Cooper-Eaton equation}

In order to study the particle rearrangement, plastic deformation and the effect of granules density and granules size range on these mechanisms, the non-linear equation proposed by Cooper and Eaton [21] was used. The model is defined by the relationship between the fractional volume compaction, $\mathrm{V}^{*}$ and the pressure, $\mathrm{P}$ as:

$V^{*}=\frac{V_{o}-V}{V_{o}-V_{\infty}}=a_{1} \exp \left(-k_{1} / P\right)+a_{2} \exp \left(-k_{2} / P\right)$

Table 1

Bulk density in $\mathrm{g} / \mathrm{cm}^{3}$ and relative density of granules (in square brackets) of studied materials.

\begin{tabular}{|c|c|c|c|c|c|}
\hline Materials & Raw material & Small-4 kN/cm & Big-4 kN/cm & Small-8 kN/cm & Big- $8 \mathrm{kN} / \mathrm{cm}$ \\
\hline MCC & 0.3 & $0.33[0.57 \pm 0.02]$ & 0.4 & $0.37[0.70 \pm 0.02]$ & 0.5 \\
\hline Mannitol & 0.48 & $0.51[0.71 \pm 0.01]$ & 0.57 & $0.55[0.79 \pm 0.01]$ & 0.6 \\
\hline
\end{tabular}

(a)

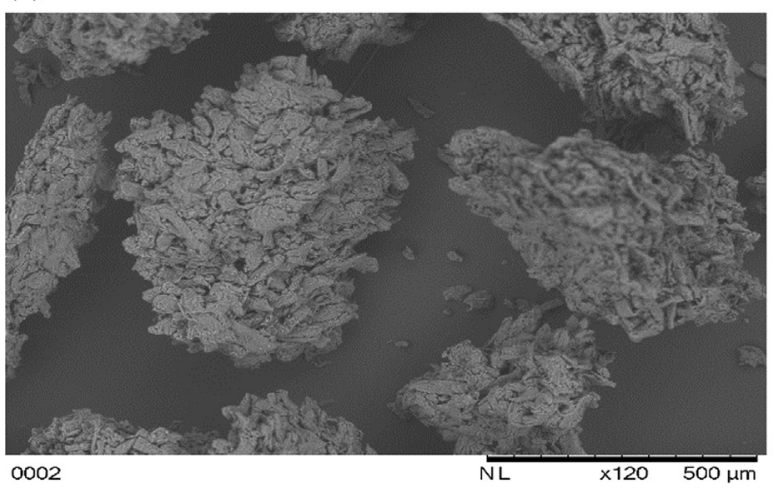

(c)

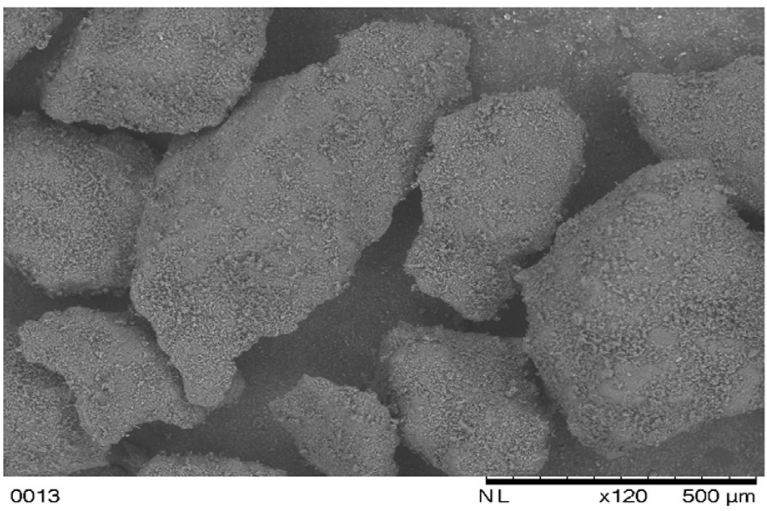

(b)

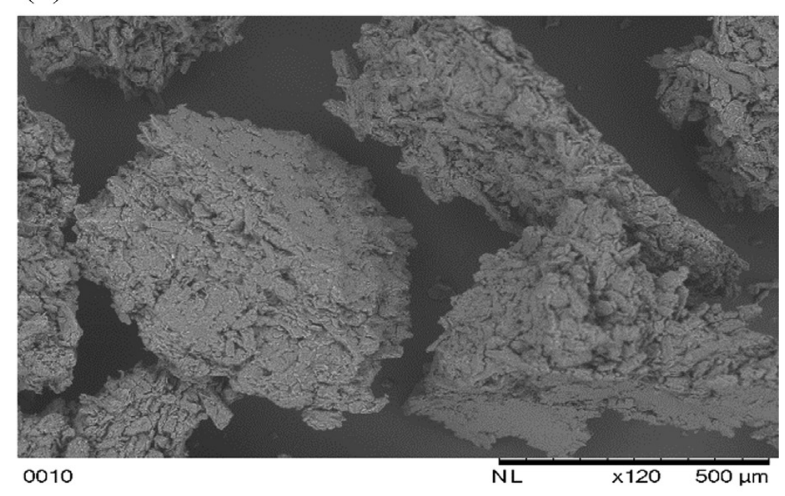

(d)

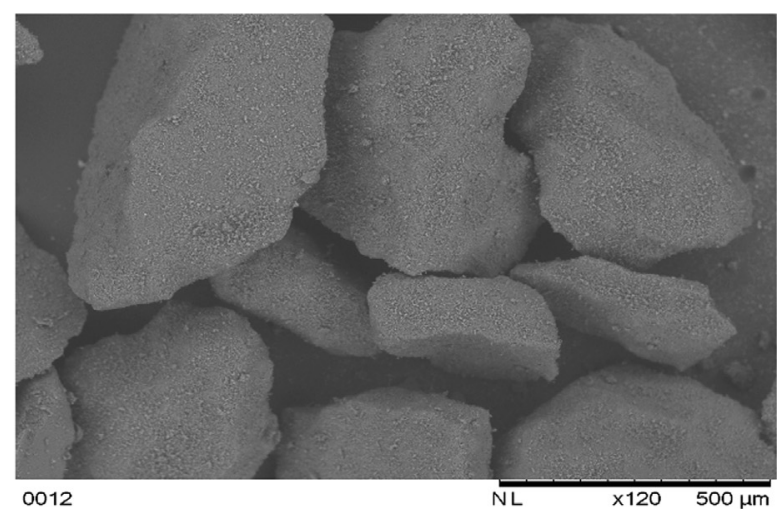

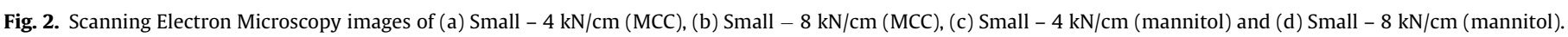


where $V_{o}$ is the initial total volume and $V_{\infty}$ is the volume of compact when all large holes, but no other holes are filled.

As all the tests were performed with the same die, Eq. (1) can be simplified as:

$\frac{h_{o}-h}{h_{0}-h_{\infty}}=a_{1} \exp \left(-k_{1} / P\right)+a_{2} \exp \left(-k_{2} / P\right)$

where $h_{0}, h$ and $h_{\infty}$ are the height of the bulk powder bed at zero pressure, the height of the compact at the pressure $P$ and the compact height at infinite pressure, respectively. $a_{1}$ and $a_{2}$ are dimensional coefficients indicating the theoretical fractional compaction achieved by particle rearrangement and plastic deformation respectively. The constants $k_{1}$ and $k_{2}$ correspond to the magnitude of the pressure at which the particle rearrangement and plastic deformation occurs respectively. Analysis of the compression data by this equation enables us to evaluate the contribution of each mechanism on the densification process according to the density and the size range of granules.

Generally, $h_{0}$ is determined from the bulk density [35]. However, this procedure was imprecise in this study due to the shape that granules can take after their filling into the die. For that, we computed $h_{0}$ from the displacement-pressure data by first determining the displacement $d_{i}$, from which the pressure starts to increase, $\mathrm{P}_{\mathrm{i}}$. These values were then used to shift the pressure and the displacement and $h_{0}$ was computed as $h_{0}=10-d_{i}$.

In the following, we refer, $V 1 *=a_{1} \exp \left(-k_{1} / P\right)$ and $V 2 *$

$$
=a_{2} \exp \left(-k_{2} / P\right)
$$

where $V_{1}{ }^{*}$ and $V_{2}{ }^{*}$ represent the fractional volume compaction by particle rearrangement and the fractional volume compaction by plastic deformation, respectively, and $V_{1}{ }^{*}+V_{2}{ }^{*}=V^{*}$.

To determine the model parameters $\left(a_{1}, a_{2}, k_{1}, k_{2}\right)$, a least square optimization method is considered using the data of the compression curve. To solve the optimization problem, the function fitnlm (fit non-linear model) proposed in MATLAB ${ }^{\circledR}$ software
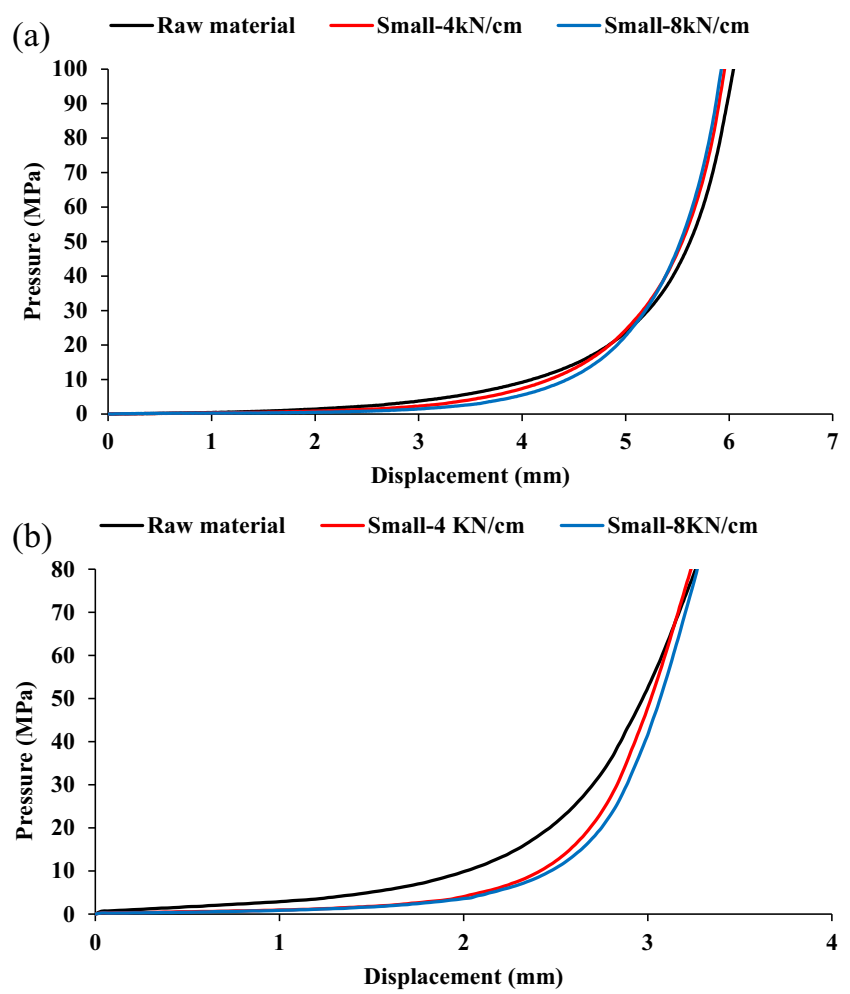

Fig. 3. Pressure versus Displacement for (a) MCC 101 and (b) mannitol. and based on the Levenberg-Marquardt algorithm [36], was employed. For this iterative algorithm, the initial condition $\left(\mathrm{a}_{1}=0.5, \mathrm{a}_{2}=0.5, \mathrm{k}_{1}=0.08, \mathrm{k}_{2}=0.5\right)$ was considered. As it can be observed, the condition $a_{1}+a_{2}=1$ is respected and $k_{1}<k_{2}$, as filling of large holes takes place at much lower pressure than filling of small holes [21]. Respecting the above conditions, the optimization problem converges to an optimum solution. Moreover, by varying the initial estimate sets, the same solution was obtained. It can be observed for the results (Table 2) that $a_{1}+a_{2}=1$ in not always respected. Similar result was reported in [31], [33] and [37].

The resulting values of each powder were summarised in Table 2. The role of the density and the size range of granules on the rearrangement and the densification mechanisms was then evaluated and compared to the corresponding raw material.

\subsection{Adams model}

The shape of the single granule is non-spherical and its strength cannot be evaluated by the compression test. In order to estimate the strength of single granule from in-die compression data, the Adams equation [23] was used:

$\ln P=\ln \left(\tau_{0}^{\prime} / \alpha^{\prime}\right)+\alpha^{\prime} \varepsilon+\ln \left(1-e^{\left(-\alpha^{\prime} \varepsilon\right)}\right)$

where $\tau_{0}{ }^{\prime}$ is the apparent single agglomerate fracture strength, $\alpha^{\prime}$ is a constant related to friction and $\varepsilon$ is the natural strain given by:

$\varepsilon=\ln \left(\frac{h_{0}}{h}\right)$

where $h$ is the height of the compact at the pressure P.

The last term of the Eq. (3) is generally negligible for higher strain and the linear part is employed to determine the parameters $\tau_{0}^{\prime}$ and $\alpha^{\prime}[23,38]$. The pressure range above $1 \mathrm{MPa}$ was considered for all the powders and the parameters $\tau^{\prime}$ and $\alpha^{\prime}$ were obtained using the least square algorithm implemented in MATLAB ${ }^{\circledR}$ software with $\mathrm{R}$-squared $>0.99$. In Table 2 were summarised the obtained parameters according to the studied materials.

\section{Results}

\subsection{Compaction behaviour}

Fig. 3(a) and (b) shows the plot of pressure versus displacement for raw material and granules of MCC101 and mannitol respectively. Despite having the same particle size range, the granules "Small-4kN/cm" and "Small-8kN/cm" have different densities (Table 1).

For MCC101, the compressive curves in Fig. 3(a) indicates that granules "Small-8kN/cm" has better compressibility as compared to "Small-4kN/cm" and raw material below $25 \mathrm{MPa}$. This behaviour highlights the good rearrangement properties of the densest granules and can be supported by the fact that the particles of "Small$8 \mathrm{kN} / \mathrm{cm}$ " show smoother and spherical surface [Fig. 2(b)] due to the higher roll compaction pressure. This leads to the reduction of the inter-particle friction which results in a slightly larger volume reduction than the particles of "Small- $4 \mathrm{kN} / \mathrm{cm}$ ". Above $25 \mathrm{MPa}$, the compressive behaviour of both kinds of granules shows more resistance to the applied pressure than raw material. This may be due to the pre-compaction of the granules which now requires more pressure to be deformed. Moreover, above $25 \mathrm{MPa}$, both granules have the same behaviour probably due to the granule breakage.

In Fig. 3(b), the deformation of mannitol powders shows that the granules are more compressible than the raw material in the whole pressure range even if raw materials have more spherical particles than the granules [Fig. 1(b) and Fig. 2(c), (d)]. Similar to 
Table 2

Cooper Eaton and Adams constants of MCC101 and mannitol.

\begin{tabular}{|c|c|c|c|c|c|c|c|c|}
\hline \multirow[t]{2}{*}{ Materials } & \multirow[t]{2}{*}{ Powder type } & \multicolumn{5}{|c|}{ Cooper-Eaton constant } & \multicolumn{2}{|l|}{ Adams } \\
\hline & & a1 & $\mathrm{a} 2$ & $\begin{array}{l}\mathrm{k} 1 \\
(\mathrm{MPa})\end{array}$ & $\begin{array}{l}\text { k2 } \\
(\mathrm{MPa})\end{array}$ & $\mathrm{R}^{2}$ & $\begin{array}{l}\tau_{o}^{\prime} \\
(\mathrm{MPa})\end{array}$ & $\alpha^{\prime}$ \\
\hline \multirow[t]{5}{*}{ MCC101 } & Raw material & 0.476 & 0.550 & 0.464 & 8.864 & 0.996 & 2.375 & 4.301 \\
\hline & Small - $4 \mathrm{KN} / \mathrm{cm}$ & 0.609 & 0.418 & 0.458 & 11.777 & 0.997 & 1.423 & 5.043 \\
\hline & Small $-8 \mathrm{KN} / \mathrm{cm}$ & 0.677 & 0.349 & 0.381 & 13.723 & 0.997 & 0.974 & 5.741 \\
\hline & $\mathrm{Big}-4 \mathrm{KN} / \mathrm{cm}$ & 0.611 & 0.40 & 0.324 & 10.151 & 0.997 & 0.960 & 5.465 \\
\hline & $\mathrm{Big}-8 \mathrm{KN} / \mathrm{cm}$ & 0.710 & 0.322 & 0.36 & 15.972 & 0.986 & 0.626 & 5.946 \\
\hline \multirow[t]{5}{*}{ Mannitol } & Raw material & 0.806 & 0.341 & 2.803 & 39.285 & 1 & 5.906 & 6.037 \\
\hline & Small $-4 \mathrm{KN} / \mathrm{cm}$ & 0.768 & 0.295 & 0.876 & 22.887 & 0.999 & 1.425 & 8.523 \\
\hline & Small $-8 \mathrm{KN} / \mathrm{cm}$ & 0.738 & 0.303 & 0.746 & 16.234 & 0.998 & 1.301 & 8.465 \\
\hline & $\mathrm{Big}-4 \mathrm{KN} / \mathrm{cm}$ & 0.739 & 0.310 & 0.774 & 18.443 & 0.996 & 1.380 & 8.533 \\
\hline & $\mathrm{Big}-8 \mathrm{KN} / \mathrm{cm}$ & 0.664 & 0.354 & 0.582 & 10.126 & 0.996 & 1.302 & 8.466 \\
\hline
\end{tabular}

MCC101, it can be observed that the granules of mannitol require more pressure than raw material for their deformation (an increase of the slope of compressive curves above $20 \mathrm{MPa}$ ).

Regarding the effect of the particle size range on the densification behaviour, no noticeable difference was observed from compressive curves of MCC and mannitol granules. These curves are not included here, but this effect will be discussed further based on Cooper-Eaton analysis.

\subsection{Compaction behaviour based on Cooper-Eaton model}

With the objective to understand the densification mechanism of the granules as a contribution of particle rearrangement and plastic deformation, the model of Cooper-Eaton was used to determine the fractional volume compaction $\mathrm{V}^{*}$ vs pressure plotted in Fig. 4(a) and (b) respectively. The constants $\mathrm{a}_{1}, \mathrm{a}_{2}, \mathrm{k}_{1}, \mathrm{k}_{2}$, were summarised in Table 2 and $\mathrm{V}^{*}$ and $\mathrm{V}_{2}{ }^{*}$ plotted in Fig. 5(a) and (b).

Fig. 4(a) shows that the fractional compaction volume of the granules is higher than that of raw material and the plot in Fig. 5 (a), shows clearly that for MCC101, the densest granules have the highest volume of rearrangement and the lowest volume of plastic deformation. Moreover, the data of Table 2 indicate that by increasing the granule density, the contribution of particle rearrangement $\left(a_{1}\right.$ coefficient) was more considerable for MCC101 (a1 $=0.47$ for raw material, 0.61 for "Small- $4 \mathrm{kN} / \mathrm{cm}$ " and 0.68 for "Small-8kN/cm"). The SEM images of the MCC granules [Fig. 2(a) and (b)] shows that "Small-8kN/cm" are smoother than "Small$4 \mathrm{kN} / \mathrm{cm}$ ", which may have improved the rearrangement. A Similar observation was reported by Kondoh et al. [39] for the rearrangement process of wet aluminium alloy powder. The constant $\mathrm{k}_{1}$, which did not show a significative difference, indicated that for both raw material and granules, the particle rearrangement was initiated at similar pressures.

In contrast, the plastic deformation coefficient $a_{2}$ decreased with the granule density, revealing that increasing the granule density, restricted the deformation capacity of the powder bed. Moreover, the higher constant $\mathrm{k}_{2}$ than $\mathrm{k}_{1}$ indicated that the filling of voids in the second stage of consolidation (plastic deformation), required higher pressure which increased with the increase of the granule density. This result highlights that the densest granules required the highest pressure to be deformed. A similar result was also obtained by Kleinebudde et al. [9] where they showed that the resistance to plastic deformation was higher with increasing specific compaction force for MCC101. This finding was consistent with SEM observation of fracture surface of the compact by diametrical test in Fig. 6, where, the densest granules ("Small$8 \mathrm{kN} / \mathrm{cm}$ ") are still intact [Fig. 6(b)] while the granules compacted at $4 \mathrm{kN} / \mathrm{cm}$ can no longer be distinguished [Fig. 6(a)].

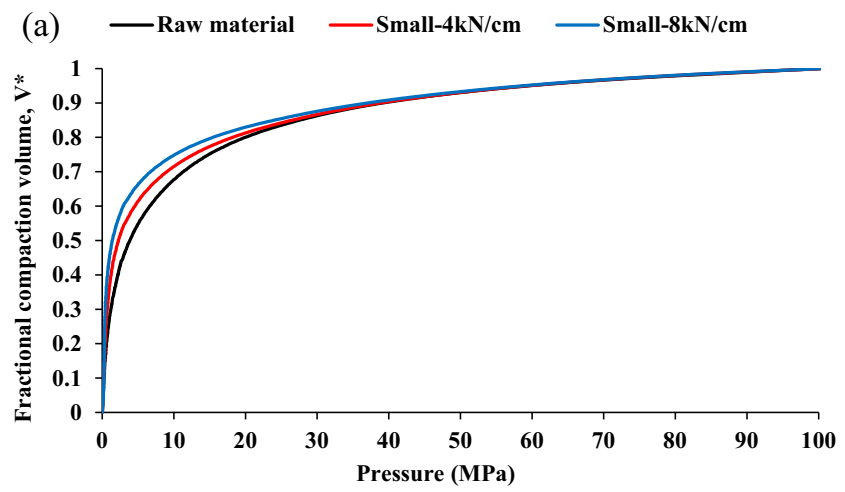

(b) Raw material - Small-4KN/cm - Small-8KN/cm

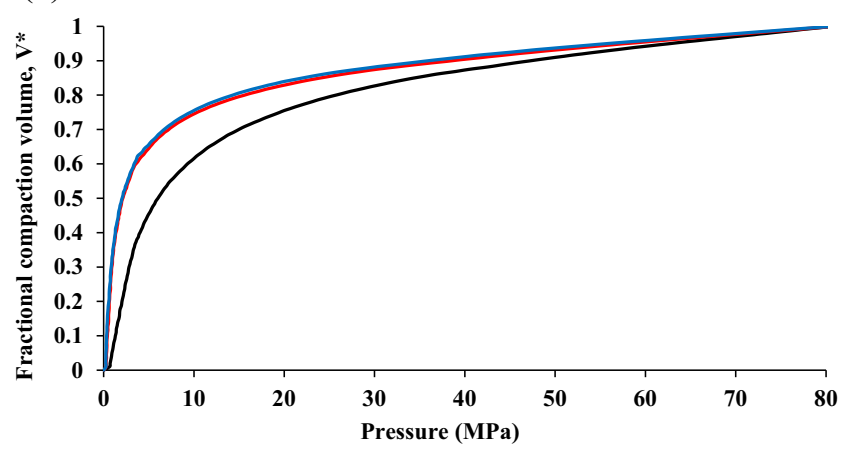

Fig. 4. Fractional volume compaction $\left(\mathrm{V}^{*}\right)$ vs pressure for (a) MCC 101 and (b) mannitol.

As mentioned earlier, the granules are neither homogeneous in density nor in size. It is therefore difficult to deconvolute these two effects on the results. Nevertheless, in this study, two size classes ([250-500 $\mu \mathrm{m}]$ and [500-1000 $\mu \mathrm{m}])$ having the same average relative density $(0.57 \pm 0.02$ and $0.70 \pm 0.02)$ were investigated. The predicted data in Table 2 did not really show a difference between the constants of small and big granules which were roll-compacted at the same force $(4 \mathrm{kN} / \mathrm{cm}$ or $8 \mathrm{kN} / \mathrm{cm})$. Although this investigation is empirical and not extended to several size classes, it could be observed in this study, that the granule size had less effect than the granule density in the densification process of dry granules. Nevertheless, the impact of granules size on tablet properties was demonstrated in $[16,38]$ where they particularly showed that granule size does not significantly affected the tablet tensile strength. In Fig. 7(a) was represented fractional volume compaction vs pressure for the granules "Small- $4 \mathrm{kN} / \mathrm{cm}$ " and "Big-4 $\mathrm{kN} / \mathrm{cm}$ " of MCC101. It can be noticed that no detectable difference can be distinguished between small and big granules. This finding is also valid for the granules roll compacted at $8 \mathrm{kN} / \mathrm{cm}$ (not 

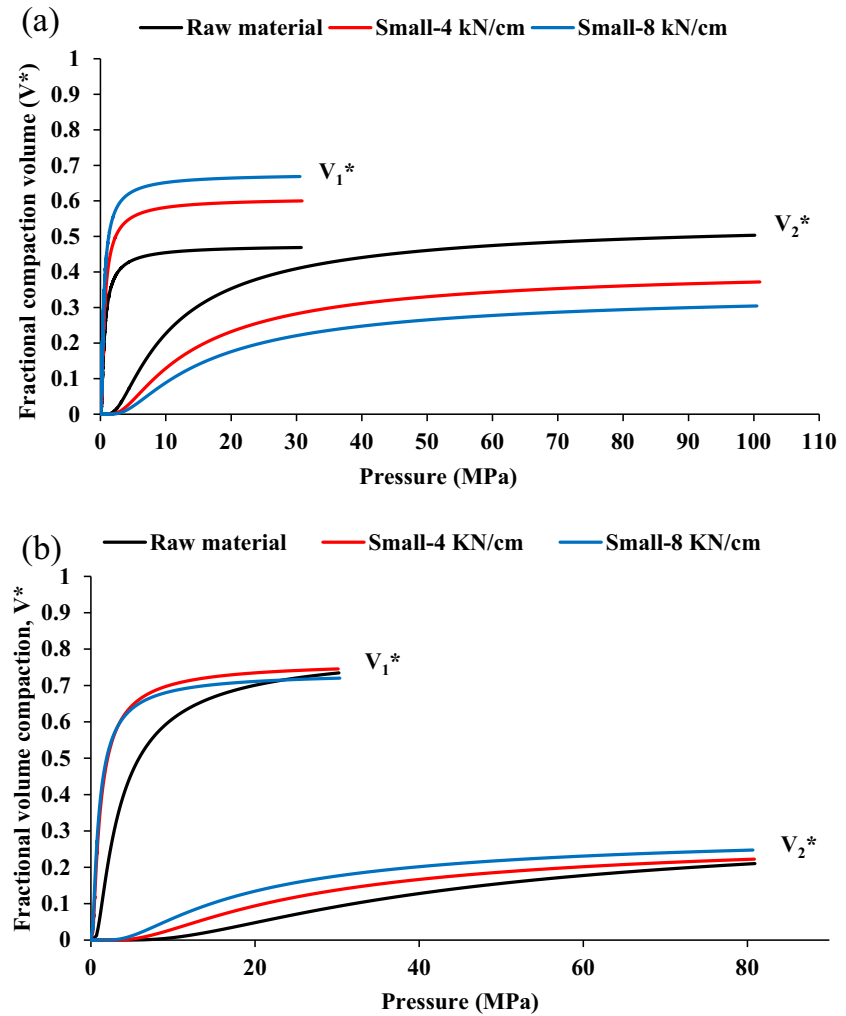

Fig. 5. Fractional volume compaction [by particle rearrangement $\left(\mathrm{V} 1^{*}\right)$ and plastic deformation (V2*)] vs pressure for (a) MCC 101 and (b) mannitol.

included here) where "Small-8 kN/cm" and "Big- $8 \mathrm{kN} / \mathrm{cm}$ " shows similar behaviour.

Regarding the densification behaviour of mannitol powders, the constant $\mathrm{a}_{1}$ showed less difference than $\mathrm{k}_{1}$. The resulting $\mathrm{V}_{1}{ }^{*}$ plotted in Fig. 5(b) highlights the good rearrangement properties of the granules, indicating that the size enlargement by dry granulation improved the relative mobility of particles under pressure. For the plastic deformation behaviour, the situation is different from that of MCC, as raw material showed the lowest fractional volume compaction by plastic deformation $\left(\mathrm{V}_{2}{ }^{*}\right)$ as shown in Fig. 5(b). However, the plot of $\mathrm{V}_{2}{ }^{*}$ shows no significant difference neither for the granules having different densities nor between raw materials and granules. Indeed, the predicted constant $\mathrm{a}_{2}$ for both of the granules was similar but slightly lower than raw material. However, the pressure $k_{2}$ required to fill the voids in the second stage of consolidation was the highest for raw material and decreased with increasing the granule density and the granule size range. This tendency is opposite to that shown by MCC101 and can be due to the brittleness of mannitol behaviour. In this context, Mosig et al. [40] found that for lactose, which is commonly considered as a brittle material, no sign of 'loss of reworkability' by increasing roll compaction force.

Regarding the effect of particle size, fractional volume compaction vs pressure for the particles "Small- $4 \mathrm{kN} / \mathrm{cm}$ " and "Big-4 $\mathrm{kN} / \mathrm{cm}$ " of mannitol was plotted in Fig. 7(b). As it can be observed, there is a slight difference between the sizes during the rearrangement and the plastic deformation. Anyway, with regard to the brittleness of the material, this difference cannot be considered as significant.

\subsection{Adams model}

The Adams constants for both materials are shown in Table 2. The result of failure strength of granules was in the range (a)

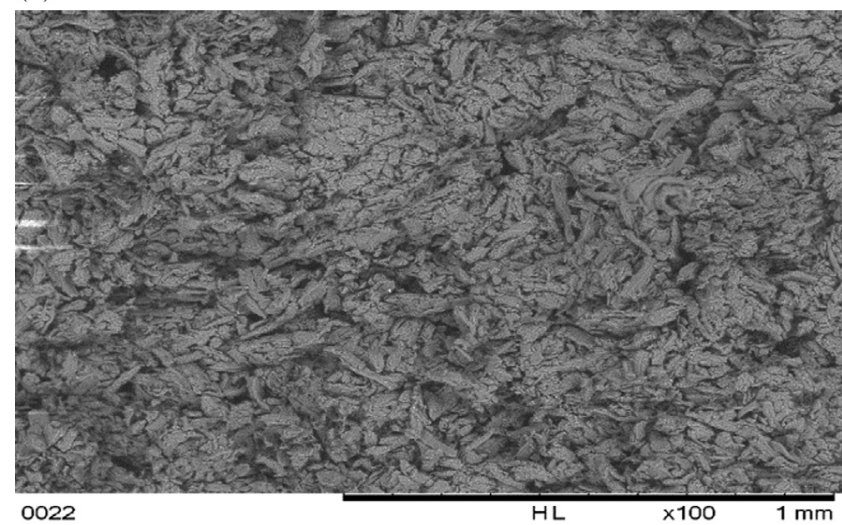

(b)

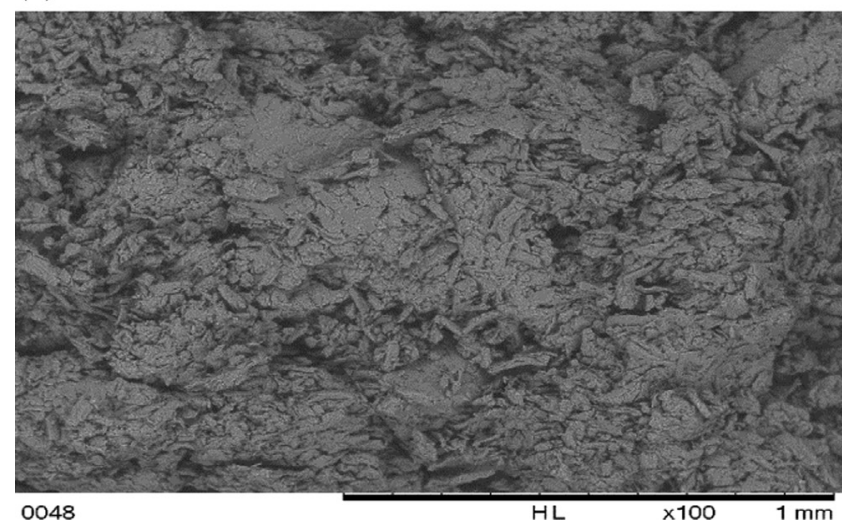

Fig. 6. Scanning Electron Microscopy images of the fracture surface of the tablets compacted at $30 \mathrm{MPa}$ for (a) Small $-4 \mathrm{kN} / \mathrm{cm}$ (MCC), (b) Small $-8 \mathrm{kN} / \mathrm{cm}$ (MCC), (c) Small $-4 \mathrm{kN} / \mathrm{cm}$ (mannitol) and (d) Small $-8 \mathrm{kN} / \mathrm{cm}$ (mannitol).

[0.6-1.43 MPa] for MCC101 and [1.3-1.43 MPa] for mannitol and did not show a clear difference between the failure strength with respect to the granule density. Particularly for MCC101, the result suggested that the granules which were roll compacted at $8 \mathrm{kN} / \mathrm{cm}$ were weaker than those roll compacted at $4 \mathrm{kN} / \mathrm{cm}$. This is unlikely to be the case as the finding is inconsistent with the above analysis using Cooper-Eaton model and also which is reported in the literature that roll compacted granules of MCC101 at higher roll force must be harder due to the work hardening $[12,40]$. For mannitol powder, a small difference was obtained between the granules failure strength, which means that the strength of the granules are almost similar for granules roll compacted at 4 or $8 \mathrm{kN} / \mathrm{cm}$. This behaviour has also been observed with regard to the tablet tensile strength of mannitol in [6] and seems to be common for brittle materials. Overall, prediction of failure strength of granules using the Adams model showed mixed results indicating that the model is not representative of the behaviour of the studied granules.

\section{Conclusion}

The objective of this study was to understand the densification mechanism of two dry granulated materials (MCC101 and mannitol) with regard to the contribution coming from particle rearrangement and plastic deformation using the model of CooperEaton. To explain the predicted constants and discuss their dependency on granule density and size, the Adams model was used to compute the failure strength of single granule from in-die compression data. 
(a)

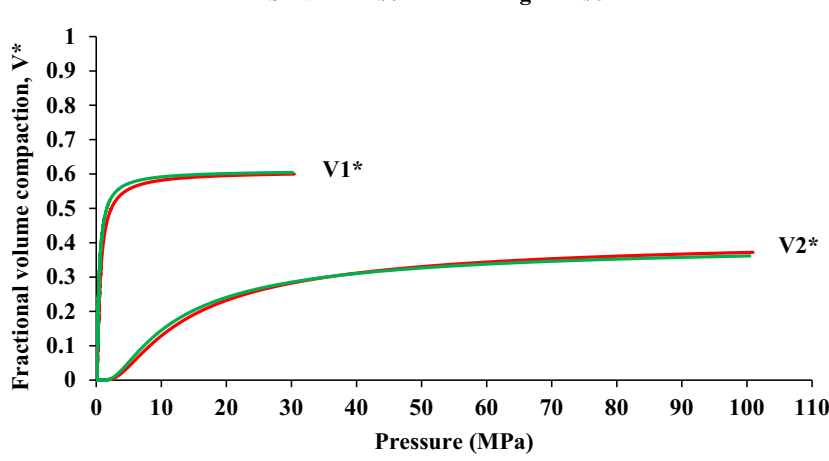

(b) $\quad$ Small - $4 \mathrm{KN} / \mathrm{cm} \quad-$ Big - $4 \mathrm{kN} / \mathrm{cm}$

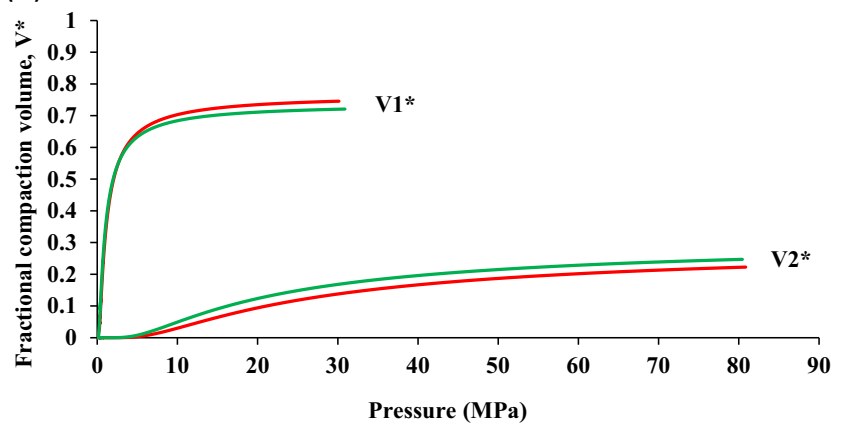

Fig.7. Fractional volume compaction [by particle rearrangement $\left(\mathrm{V} 1^{*}\right)$ and plastic deformation (V2*)] vs pressure for (a) MCC 101 and (b) mannitol.

For MCC101 material, the Cooper-Eaton model was able to quantify and explain the rearrangement and the plastic deformation stages of raw material and granules during the densification process. The model also captured the effect of the granule density and granule size on the rearrangement and plastic deformation mechanism. This information could not be directly retrieved from the compressive curves and demonstrated the relevance of the model to better understand the densification mechanism. However, when applied to mannitol powder, the model showed mixed results which cannot improve the understanding of granule densification mechanisms. On another hand, the failure strength of granules computed by Adams model showed values in the range [0.6-1.43 MPa] for MCC 101 and in the range [1.3-1.43 MPa] for mannitol. These values were lower than those reported in [41] for monodisperse granules which were obtained by diecompaction, with a similar solid fraction. It should be noted here that the Adams model was derived for near spherical particles with a narrow size distribution while in this study, the granules are not spherical and have a relatively wide range of sizes.

\section{Acknowledgements}

Special thanks are addressed to Professor P. Kleinebudde and his staff from University of Dusseldorf, Germany, for allowing us to use the roll compactor and their support during manufacturing of granules.

\section{References}

[1] R.W. Miller, Roller Compaction Technology, in: D.M. Parikh (Ed.), Handbook of pharmaceutical Granulation Technology, Taylor \& Francis Group, London, 2005, pp. 159-190.

[2] S. Inghelbrecht, J.P. Remon, The roller compaction of different types of lactose, Int. J. Pharm. 166 (1998) 135-144
[3] F. Freitag, K. Reincke, J. Runge, W. Grellmann, P. Kleinebudde, How do roll compaction/dry granulation affect the tableting behaviour of inorganic materials? Micro hardness of ribbons and mercury porosimetry measurements of tablets, Eur. J. Pharm Sci. 22 (2004) 325-333.

4] A.K. Samanta, K.Y. Ng, P.W. Heng, Cone milling of compacted flakes: process parameter selection by adopting the minimal fines approach, Int. J. Pharm. 422 (1-2) (2012) 17-23.

[5] C.M. Wagner, M. Pein, J. Breitkreutz, Roll compaction of mannitol: compactability study of crystalline and spray-dried grades, Int. J. Pharm. 453 (2013) 416-422.

[6] L. Perez-Gandarillas, A. Perez-Gago, A. Mazor, P. Kleinebudde, O. Lecoq, A. Michrafy, Effect of roll-compaction and milling conditions on granules and tablet properties, Eur. J. Pharm. Biopharm. 106 (2016) 38-49.

[7] A. Mazor, L. Perez-Gandarillas, Alain De Ryck, A. Michrafy, Effect of roll compactor sealing system designs: a finite element analysis, Powder Technol. 289 (2016) 21-30.

[8] J.M. Bultmann, Multiple compaction of microcrystalline cellulose in a roller compactor, Eur. J. Pharm. Biopharm. 54 (2002) 59-64.

[9] M.G. Herting, P. Kleinebudde, Studies on the reduction of tensile strength of tablets after roll compaction/dry granulation, Eur. J. Pharm. Biopharm. 70 (2008) 372-379.

[10] E. Gavi, G.K. Reynolds, System model of a tablet manufacturing process, Comput. Chem. Eng. 71 (2014) 130-140.

[11] A.D. Rajkumar, G.K. Reynolds, D. Wilson, S. Wren, M.J. Hounslow, A.D. Salman, Investigating the effect of processing parameters on pharmaceutical tablet disintegration using a real-time particle imaging approach, Eur. J. Pharm. Biopharm. 106 (2016) 88-96.

[12] S. Malkowska, K.A. Khan, Effect of recompression on the properties of tablets prepared by dry granulation, Drug Dev. Ind. Pharm. 9 (1983) 331-347.

[13] C. Sun, M.W. Himmelspach, Reduced tabletability of roller compacted granules as a result of granule size enlargement, J. Pharm. Sci. 95 (1) (2006) 200-206.

[14] M.G. Herting, P. Kleinebudde, Roll compaction/dry granulation: effect of raw material particle size on granule and tablet properties, Int. J. Pharm. 338 (1-2) (2007) 110-118.

[15] S.J. Wu, C. Sun, Insensitivity of compaction properties of brittle granules to size enlargement by roller compaction, J. Pharm. Sci. 96 (2007) 1445-1450.

[16] L. Perez-Gandarillas, A. Mazor, O. Lecoq, A. Michrafy, Compaction properties of dry granulated powders based on Drucker-Prager Cap model, Powder Technol. 337 (2018) 43-50.

[17] J. Zhao, H.M. Burt, R.A. Miller, The Gurnham equation in characterizing the compressibility of pharmaceutical materials, Int. J. Pharm. 317 (2006) 109113.

[18] E.E. Walker, The properties of powders VI: the compressibility of powders, Trans. Faraday Soc. 19 (1923) 73-82.

[19] R.W. Heckel, An analysis of powder compaction phenomena, Trans. Metall. Soc. AIME 221 (1961) 1001-1008.

[20] R.W. Heckel, Density-pressure relationships in powder compaction, Trans. Metall. Soc. AIME 221 (1961) 671-675.

[21] A.R. Cooper, L.E. Eaton, Compaction behaviour of several ceramic powders, J. Am. Ceram. Soc. 45 (3) (1962) 97-101.

[22] K. Kawakita, K. Ludde, Some considerations on powder compression equations, Powder Technol. 4 (1971) 61-68.

[23] M.J. Adams, M.A. Mullier, J.P.K. Seville, Agglomerate strength measurement using a uniaxial confined compression test, Powder Technol. 78 (1994) 5-13.

[24] M. Kuentz, H. Leuenberger, Pressure susceptibility of polymer tablets as a critical property: a modified Heckel equation, J. Pharm. Sci. 88 (1999) 174179.

[25] M. Celik, Overview of compaction data analysis techniques, Drug Dev. Ind. Pharm. 18 (1992) 767-810.

[26] F. MAHMOODI, Compression Mechanics of Powders and Granular Materials Probed by Force Distributions and a Micromechanically Based Compaction Equation. Uppsala: Acta Universitatis Upsaliensis, 2012.

[27] R.C. Rowe, R.J. Roberts, In: Alderborn, G., Nystrom, C. (Eds.), Mechanical Properties. Marcel Dekker Inc., New York Basel, 1996. pp. 283-322.

[28] J.T. Fell, J.M. Newton, Effect of particle size and speed of compaction on density changes in tablets of chrystalline and spray-dried lactose, J. Pharm. Sci. 60 (1971) 1866-1869.

[29] J.T. Fell, M. Sheikh-Salem, The influence of initial packing on the compression of powders, J. Pharm. Pharmacol. 33 (1981) 491-494.

[30] Z.T. Chowhan, Y.P. Chow, Compression behaviour of pharmaceutical powders, Int. J. Pharm. 5 (1980) 139-148.

[31] P. Paronen, M. Juslin, Compressional characteristic of four starches, J. Pharm. Pharmacol. 35 (1983) 627-635.

[32] T. Itoh, Y. Wanibe, Relationship between compacting behaviours and morphological characteristics for metallic powders, J. Jpn Soc. Powder Powder Metall. 46 (1999) 16-21.

[33] Y. Zhang, Y. Law, S. Chakrabarti, Physical properties and compact analysis of commonly used direct compression binders, AAPS Pharm. SciTech. 4 (4) (2003) 489-499.

[34] A. Michrafy, H. Diarra, J.A. Dodds, Compaction behaviour of binary mixtures, Powder Technol. 190 (2008) 146-151.

[35] H.R. Hafizpour, A. Simchi, S. Parvizi, Analysis of the compaction behavior of Al$\mathrm{SiC}$ nanocomposites using linear and non-linear compaction equations, Adv. Powder Technol. 21 (2010) 273-278.

[36] G.A.F. Seber, C.J. Wild, Nonlinear Regression, Wiley-Interscience, Hoboken, NJ, 2003. 
[37] P. Paronen, J. Iilla, Porosity-pressure functions, in: G. Alderborn, C. Nystrom (Eds.), Pharmaceutical powder compaction technologies, Marcel Dekker Inc, New York, NY, 1996, pp. 55-75.

[38] F. Nicklasson, G. Alderborn, Analysis of the compression mechanics of pharmaceutical agglomerates of different porosity and composition using the Adams and Kawakita equations, Pharm Res. 17 (2000) 949-954.

[39] K. Kondoh, R. Watanabe, H. Hashimoto, Analysis of compaction behaviour of wet granulated aluminum alloy powder, Powder Metall. 46 (7) (2000) 780786.
[40] J. Mosig, P. Kleinebudde, Critical evaluation of root causes of the reduced compactability after roll compaction/dry granulation, J. Pharm. Sci. 104 (2015) 1108-1118.

[41] B. Mitra, J. Hilden, J.D. Lister, Novel use of monodisperse granules to deconvolute impacts of granule size versus granule solid fraction on tablet tensile strength, Adv. Powder Technol. 26 (2015) 553-562. 